\title{
Transient Low Testosterone Levels After Oral Hydrocodone May Contribute to Misdiagnosis of Hypogonadism
}

\author{
Harry W. Daniell
}

\begin{abstract}
Alterations in luteinizing hormones and testosterone levels following short-acting opioid ingestion are unknown but may assist in the diagnosis of hypogonadism in opioid consumers. Serial luteinizing hormones and testosterone values were measured every 2 hours for 10 hours following ingestion of either 0,5 , or $10 \mathrm{mg}$ of hydrocodone on multiple isolated occasions, and demonstrated testosterone levels 2 and 4 hours after $10 \mathrm{mg}$ ingestion to be $25 \%$ lower than those after 0 or $5 \mathrm{mg}$, with this difference resolving within 8 post-ingestion hours, indicating that knowledge of recent hydrocodone ingestion may be valuable in interpreting the significance of low morning testosterone levels in some patients.
\end{abstract}

Keywords: Testosterone; Hydrocodone; Opioids; Misdiagnosis; Hypogonadism

\section{Introduction}

The daily use of sustained-action opioids induces testosterone deficiency in a dose-related pattern [1], with morning free testosterone (FT) and total testosterone (TT) levels averaging $40 \%$ lower in men with daily consumption of 20 - 60 methadone standard equivalents (MSEs) than in non-opioid consumers [1]. Morning testosterone levels may be temporarily below normal limits in men without hypogonadism, contributing to the recommendation that low morning testosterone levels be interpreted as supporting a diagnosis of hypogonadism only after confirmation by repeat examination [2].

Recent reports, however, exploring the frequency of opioid-associated hypogonadism in patients receiving shortacting opioids [3] or the response to testosterone therapy of patients with opioid-induced androgen deficiency (OPIAD) [4] defined hypogonadism by utilizing only a single morning testosterone measurement.

The 2 - 4 h duration of hydrocodone-induced analgesia [5]

Manuscript accepted for publication December 11, 2015

Department of Family Practice, University of California Medical School at Davis, Davis, CA, USA. Email: hwdaniell@aol.com

doi: http://dx.doi.org/10.14740/jem324w and the $3.8-4.2 \mathrm{~h}$ hydrocodone half-life after ingestion of a single $10 \mathrm{mg}$ dose $[6,7]$ are compatible with brief duration of any post-ingestion inhibition of testosterone formation, supporting the possibility that this ingestion shortly before testosterone measurement might jeopardize its value in establishing a diagnosis of hypogonadism.

To aid in defining the duration and intensity of any depression of morning testosterone levels following the isolated ingestion of hydrocodone, we documented these levels on multiple occasions in a 72-year-old man.

\section{Case Report}

Luteinizing hormone (LH) and TT levels were measured by RAI and FT levels were determined by equilibrium dialysis, each measured at 07:00 and every $2 \mathrm{~h}$ thereafter for $10 \mathrm{~h}$, once weekly, for 22 weeks, in a fasting, apparently healthy 72 -yearold opioid-naive, non-obese, non-diabetic, non-hypertensive, medication-free man. After each 07:00 sampling, he ingested either no hydrocodone or a single dose of 5 or $10 \mathrm{mg}$ in a random pattern followed by $1 \mathrm{~h}$ of fasting.

After ingestion of $5 \mathrm{mg}$ of hydrocodone, FT levels and TT values were not significantly different from those following no hydrocodone, each demonstrating a progressive $25 \%$ decrease in a diurnal pattern. Two hours and $4 \mathrm{~h}$ after $10 \mathrm{mg}$ ingestion, however, average FT levels averaged $25 \%$ lower than those at the same interval following 0 or $5 \mathrm{mg}(\mathrm{P}<0.001)$, with two individual FT measurements falling below the lower normal limit of our laboratory $(50 \mathrm{pg} / \mathrm{mL})$. Eight and $10 \mathrm{~h}$ post-ingestion, testosterone levels were again not significantly lower than those following lower doses. The range of FT levels at each interval since ingestion of each hydrocodone dose was unrelated to the post-ingestion interval and this range did not change significantly over the duration of the study. Individual and average FT values are presented in Figure 1. LH levels were unrelated to hydrocodone doses or to the interval since hydrocodone ingestion.

\section{Discussion}

Our data strongly support consistent inhibition of testosterone production in our subject by a single oral $10 \mathrm{mg}$ dose of hydrocodone in a pattern most prominent $2-4 \mathrm{~h}$ post-ingestion and with resolution of this inhibition largely completed $8 \mathrm{~h}$ 


\section{HYDROCODONE DOSE}

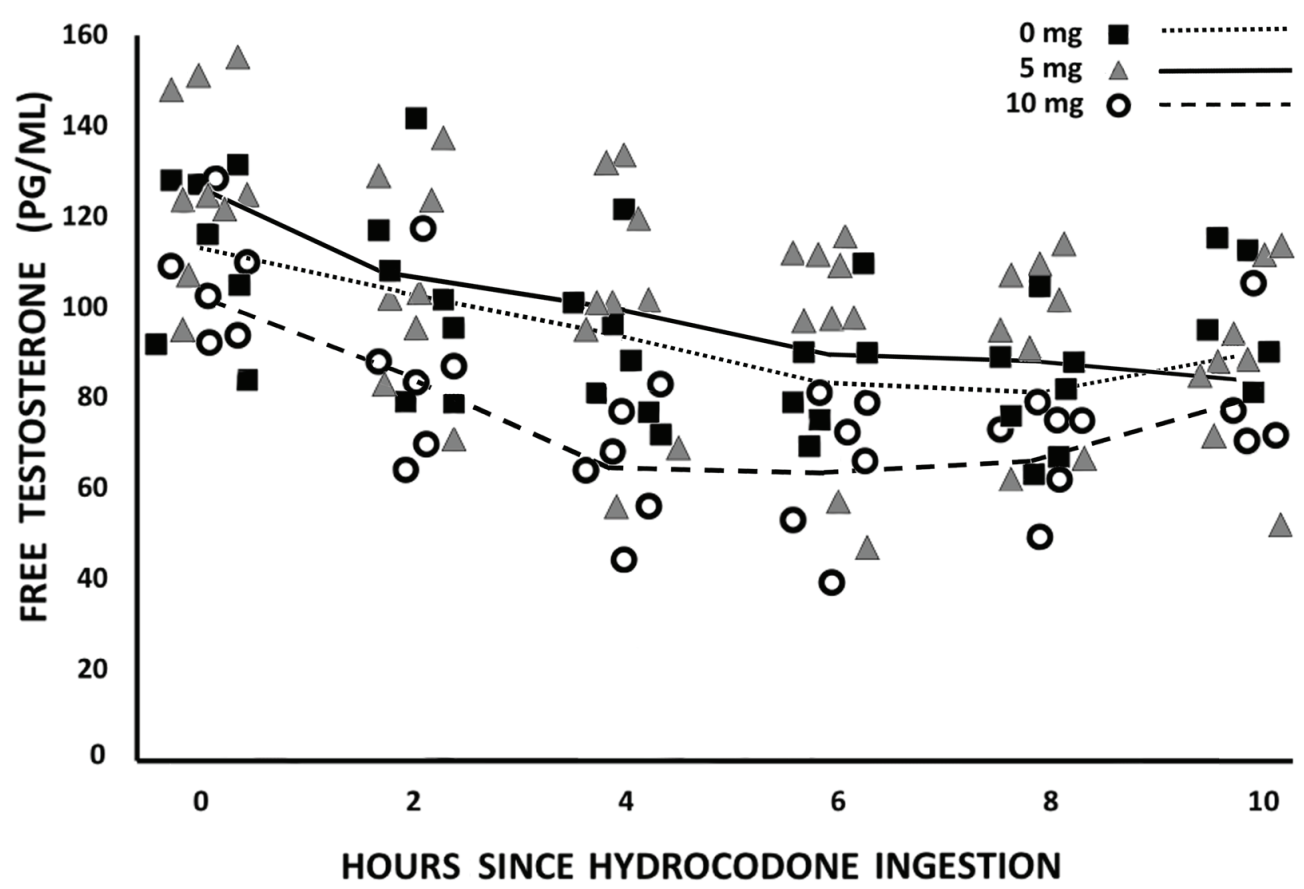

Figure 1. Free testosterone responses to oral hydrocodone followed by a 1 hour fast in an opioid-naive subject. Each symbol represents an independent observation. Lines indicate average values from observations at each hour.

post-ingestion. These observations are compatible with this inhibition being induced by serum hydrocodone levels diminishing in their concentrations during metabolism at its $4 \mathrm{~h}$ halflife, and support a contribution by this inhibition to an inappropriate diagnosis of hypogonadism in many of the low-dose short-acting opioid consumers included in two recent studies $[3,4]$.

Rubinstein and Carpenter [3] reported the frequency of at least one morning testosterone level below $250 \mathrm{ng} / \mathrm{dL}$ in $35 \%$ of 965 men who had no prior diagnosis of androgen deficiency and within 90 days following receipt of a 3-month supply of a daily short-acting opioid, no other opioid has been prescribed. One milligram of hydrocodone represented one MSE and prescribed daily opioid doses were limited to 20 or fewer MSE in $25 \%$ of subjects and 40 or fewer MSE in $75 \%$. This $35 \%$ frequency was lower than the 57\% in 616 men in their study for whom long-acting opioids had been similarly prescribed in a daily dose averaging five times as large (150 MSE vs. $30 \mathrm{MSE})$; however, no testosterone observations from suitable control opioid non-consumers were obtained. The number of testosterone measurements from which each qualifying level had been selected and the time of day of any opioid consumption preceding testosterone measurement were also not reported.

Utilizing a similar technique for determining hypogonadism, Basaria et al [4] reported results of a placebo-controlled trial including 85 men which was designed to evaluate the effectiveness among them on the signs and symptoms of OPIAD during 14 weeks of daily application of $10 \%$ testoster- one gel sufficient to raise testosterone levels to normal. Eligibility for their study required only a single morning TT level under $350 \mathrm{ng} / \mathrm{dL}$ preceded by 4 weeks of $20 \mathrm{mg}$ or more of daily hydrocodone or its MSE. Whether this dose consisted of short-acting, or sustained-acting opioids, or of a combination of opioid dosage forms was not reported. The value of their observations seems limited, however, by multiple factors. The average MSE consumption of daily completers in their testosterone arm was $50 \%$ higher than that in the 29 completers in their placebo arm. Any changes in opioid consumption since study entry or in the hour of its ingestion were not reported, but morning testosterone levels had become $450 \mathrm{ng} / \mathrm{dL}$ or higher in the upper quartile of the 29 placebo-treated completers, indicating the inclusion in this arm of many subjects who were likely eugonadal at study completion, or who had decreased their opioid consumption during participation. The observations also suggest the possibility of inclusion in both study arms of patients who may have been eugonadal at study entry.

The observations in our single subject indicate a need for studies examining the influence of short-acting opioids on testosterone levels in other subjects of varying age, body mass index, and general health. They also support the weakness in the interpretation of morning testosterone levels for the diagnosis of clinically relevant hypogonadism in patients whose recent short-acting opioid ingestion is unknown, and reinforce the value of multiple testosterone levels measured on different mornings to help protect men from the hazards of inappropri- 
ate testosterone therapy.

\section{Disclosure}

The author has nothing to disclose.

\section{Grants}

There were no grants or fellowships involved in this paper.

\section{References}

1. Daniell HW. Hypogonadism in men consuming sustained-action oral opioids. J Pain. 2002;3(5):377-384.

2. Bhasin S, Cunningham GR, Hayes FJ, Matsumoto AM, Snyder PJ, Swerdloff RS, Montori VM. Testosterone therapy in men with androgen deficiency syndromes: an Endocrine Society clinical practice guideline. J Clin Endocrinol Metab. 2010;95(6):2536-2559.

3. Rubinstein A, Carpenter DM. Elucidating risk factors for androgen deficiency associated with daily opioid use. Am J Med. 2014;127(12):1195-1201.

4. Basaria S, Travison TG, Alford D, Knapp PE, Teeter K, Cahalan C, Eder R, et al. Effects of testosterone replacement in men with opioid-induced androgen deficiency: a randomized controlled trial. Pain. 2015;156(2):280-288.

5. McRae AL, Sonne SC. Opioid Equivalency: A Review. J Pharm Prac. 1998;11:394-404.

6. Barnhart JW, Caldwell WJ. Gas chromatographic determination of hydrocodone in serum. J Chromatogr. 1977; 130:243-249.

7. Otton SV, Schadel M, Cheung SW, Kaplan HL, Busto UE, Sellers EM. CYP2D6 phenotype determines the metabolic conversion of hydrocodone to hydromorphone. Clin Pharmacol Ther. 1993;54(5):463-472. 